\title{
SEXUAL BEHAVIOR AND AGGRESSION IN MALE MICE: INVOLVEMENT OF THE VOMERONASAL SYSTEM ${ }^{1}$
}

\author{
ANDREW N. CLANCY, ${ }^{* 2}$ ARTHUR COQUELIN, $\ddagger$ FOTEOS MACRIDES, ${ }^{*}$ ROGER A. GORSKI, $\ddagger$ AND \\ ERNEST P. NOBLE§
}

* Worcester Foundation for Experimental Biology, Shrewsbury, Massachusetts 01545, and $\ddagger$ Department of Anatomy and Laboratory of Neuroendocrinology of the Brain Research Institute and \$Alcohol Research Center, Department of Psychiatry and Biobehavioral Sciences, University of California, Los Angeles, School of Medicine, Los Angeles, California 90024

Received November 23, 1983; Revised March 14, 1984; Accepted March 21, 1984

\begin{abstract}
Recent observations have implicated the vomeronasal (accessory olfactory) system in the chemosensory control of rodent social behaviors. The purpose of this study was to observe the effects of peripheral vomeronasal organ extirpation on sexual behavior, aggression, and urine marking in male mice. Relative to sham-operated control animals, mice lacking vomeronasal organs displayed significantly reduced levels of copulatory behavior and intermale aggression. Urine marking rates were not reduced. The peripheral removal of the vomeronasal organ resulted in complete bilateral deafferentation of the accessory olfactory bulbs but spared the peripheral input to the main olfactory bulbs as evidenced by the lack of anterograde vomeronasal nerve transport but normal anterograde olfactory nerve transport of intranasally applied horseradish peroxidase. Neither body weights, paired testes weights, nor seminal vesicle weights of mice with vomeronasal system lesions differed significantly from those of control animals. Thus, an intact vomeronasal organ is important for the normal display of sexual behavior and aggression in male mice, and the reductions in these androgen-dependent behaviors following peripheral deafferentation of the vomeronasal system cannot be attributed to a chronic reduction of gonadal hormone secretion.
\end{abstract}

Chemosensory stimuli and the olfactory system influence reproductive physiology and behavior in a broad range of mammalian species. Numerous examples of these influences are known. Male mice excrete androgen-dependent urinary compounds that accelerate puberty in young conspecific females (Vandenbergh, 1967, 1969; Kennedy and Brown, 1970; Zarrow et al., 1970; Bronson and Desjardins, 1974), synchronize estrus among noncycling adult females (Whitten, 1957; Marsden and Bronson, 1964; Bronson and Dezell, 1968; Bronson and Whitten, 1968; Whitten et al., 1968), and block pregnancy (Bruce, 1959; Bronson and Eleftheriou, 1963). Moreover, ovulation may be induced in female rats by the urine of conspecific males (Johns et al., 1978). Similarly, females of many mammalian species produce stimuli that acutely alter the reproductive status of conspecific males. Male mice (Macrides et al., 1975; Coquelin and Bronson, 1980), rats (Purvis and Haynes, 1974; Kanel et al., 1975, 1977; Kamel and Frankel, 1978), rabbits (Saginor and Horton, 1968; Haltmeyer and Eik-Nes, 1969), bulls (Katongole et al., 1971), and hamsters (Macrides et al., 1974) show acute rises in circulating luteinizing hormone (LH) and/or testosterone ( $\mathrm{T}$ ) levels when stimulated by conspecific

${ }^{1}$ This research was supported by United States Public Health Service Fellowships MH 08645 and HD 06160 and Research Grants NS 12344, HD 01182, and AA 05555, and by the Seaver Institute.

${ }^{2}$ To whom correspondence should be addressed, at Worcester Foundation for Experimental Biology, 222 Maple Avenue, Shrewsbury, MA 01545 . females. Chemical stimuli frequently serve as sexual attractants. Moreover, the gonadal hormonal status of both the sender and receiver often affects the production of and the responses toward such compounds (Bruce, 1965; Leshner, 1978).

Damage to olfactory structures impairs a range of reproduction-related and social behaviors. Thus, female mice and hamsters fail to build nests or display maternal care following bilateral olfactory bulbectomy (Gandelman et al., 1971, 1972; Zarrow et al., 1971; Vandenbergh, 1973; Marques, 1979). The bilateral removal of the olfactory bulbs retards copulatory behavior in male rats (Heimer and Larsson, 1967; Bermant and Taylor, 1969; Larsson, 1971) and in females of a variety of rodent species (Moss, 1971; Thompson and Edwards, 1972; Edwards and Burge, 1973; Vandenbergh, 1973). Indeed, such lesions completely eliminate sexual behavior in male hamsters (Murphy and Schneider, 1970; Winans and Powers, 1974) and male mice (Rowe and Edwards, 1972; Rowe and Smith, 1973; Edwards, 1974). In addition, olfactory bulbectomy generally blocks a wide range of pheromonally mediated responses (Leshner, 1978) and eliminates intraspecific aggression in male mice (Ropartz, 1968; Rowe and Edwards, 1971; Denenberg et al., 1973; Neckers et al., 1975; Bean, 1982a). Unfortunately, in addition to producing anosmia, such central lesions also disturb multiple neural subsystems within the brain (Alberts, 1974; Cain, 1974; Hirsch, 1980; Hall and Macrides, 1983). Accordingly, the particular neural subsystems mediating specific behaviors often cannot be defined.

Peripheral receptor neurons within the vomeronasal organ 
(VNO) innervate the accessory olfactory bulb (AOB) and are anatomically independent of the olfactory receptor neurons within the olfactory epithelium, which project to the main olfactory bulh (MOB) (Barber and Raisman, 1974; Wysocki, 1979). The MOB and AOB, in turn, have distinct projections to more central structures (Scalia and Winans, 1975; Macrides and Davis, 1983). Efferents of the AOB project into amygdaloid and basal forebrain areas which are heavily labeled by radioactive gonadal steroids and which have been implicated in reproductive functions (Winans and Scalia, 1970; Wysocki, 1979). Accordingly, it is believed that the vomeronasal system plays a role in reproduction (Winans and Scalia, 1970; Scalia and Winans, 1974; Wysocki, 1979; Lehman et al., 1980; Lehman and Winans, 1982). Indeed, vomeronasal system lesions disturb sexual behavior in male hamsters (Powers and Winans, 1975; Meredith et al., 1980) and ultrasonic courtship vocalizations in male mice (Bean, 1982b; Wysocki et al., 1982). Moreover, damage of the vomeronasal system blocks a variety of pheromonally mediated responses in mice including pregnancy block (Bellringer et al., 1980), puberty acceleration (Kaneko et al., 1980), estrus suppression (Reynolds and Keverne, 1979), and the female-elicited LH/T surge in males (Wysocki et al., 1983; Coquelin et al., 1984).

In the present study it was hypothesized that male mice with selective vomeronasal system lesions would show impaired mating behavior and impaired urine marking, a behavior associated with the dissemination of pheromones (Desjardins et al., 1973). Furthermore, it was hypothesized that male mice with such lesions would show reduced levels of aggressive behavior. This is because such responses are strongly dependent upon chemosensory stimulation (Mugford and Nowell, 1970; Connor, 1972). Moreover, previous research has demonstrated a reduction in aggressiveness among male mice as a consequence of vomeronasal system damage (Bean, 1982a). Accordingly, the behavioral consequences of selective peripheral deafferentation of the AOB were studied. Specifically, the VNO was extirpated from male mice, and copulatory behavior, aggressive behavior, and urinary marking were observed. The extent of peripheral deafferentation of the $\mathrm{AOB}$ and the sparing of the olfactory nerve input to the MOB were verified by examining the anterograde transport of intranasally administered horseradish peroxidase (HRP).

\section{Materials and Methods}

Animals. Male CF-1 mice that ranged in age from 99 to 141 days at the start of postsurgical testing were used. Mice were obtained from the Charles River Breeding Laboratories, Inc. (Wilmington, MA), and, immediately upon arrival, each was housed in a $29 \times 18 \times 13 \mathrm{~cm}$ plastic cage in a colony room maintained at 22 to $24^{\circ} \mathrm{C}$ on a 14 -hr light/10-hr dark photoperiod, with Purina Mouse Chow and tap water always available. During the next 15 consecutive days, each male cohabited with three different sexually mature females, being paired with each female for 5 consecutive days. The females were inspected daily for the presence of copulatory plugs, and only males that mated with at least one female were retained as subjects. The males were individually housed during the remainder of the study, and exposure to the social stimuli occurred in each male's home cage.

Surgical procedures. Immediately after the social experience pairings were completed, males were randomly divided into two groups of 10 animals each. Experimental mice (Group VOX) received lesions of the vomeronasal system. These lesions were produced by anesthetizing the animals with sodium pentobarbital and securing them on a glass plate with their ventral surfaces up. The glass plate was tilted so that the noses of the mice were lower than the rest of their bodies. This reduced bleeding into the oral and respiratory passages. The mouths of the animals were opened with loose silk ties around the upper and lower incisors. Midline incisions were made in the palates to provide access to the VNOs. The tissues were retracted and the VNOs were detached from the ventral surfaces of the skulls by drilling at both the anterior and posterior points of attachment. The VNOs were then lifted from the nasal cavities and inspected under a surgical stereomicroscope to ensure that they were intact and that the encapsulated epithelial tissues were present bilaterally. The nasal and oral cavities were then aspirated until all bleeding stopped. The wounds were closed using 6-0 surgical silk and collodian. Control mice (Group SHAM) were treated identically except that no drilling was performed and the VNOs were not manipulated or removed. All VOX and SHAM mice were inspected 1 week after surgery to ensure that their palates had healed completely. All 20 animals were also prepared with chronic indwelling, intra-atrial catheters 1 week after they received their lesions or sham operations. This procedure has been described elsewhere (Coquelin and Bronson, 1980). Fxactly as described in the companion report on spontaneous and stimulus-induced LH surges (Coquelin et al., 1984), 17 of the 20 mice in this study were bled and LH levels were measured. These hormonal data are included in the companion report (Coquelin et al., 1984).

Behavioral testing. Postsurgical behavioral testing began after a lesion recovery period of 23 to 65 days. All tests were performed during the light phase of the illumination cycle. Data were collected by observers who were not familiar with the surgical histories of the subjects.

The first sexual behavior test consisted of pairing each male with a single ovariectomized stimulus female for $15 \mathrm{~min}$. The number of attempted mounts and the latency of the first attempted mount were recorded for each subject.

The second sexual behavior test took place 6 to 7 days after the first and consisted of pairing each male with a sexually receptive female partner. Stimulus females were gonadally intact, ranged in age from 30 to 35 days, and were rendered sexually receptive by injecting them with pregnant mare serum followed by human chorionic gonadotropin (Edwards et al., 1963). The test length was $60 \mathrm{~min}$. If the subject mounted the female within $15 \mathrm{~min}$ it remained paired with the same female for the duration of the test. However, if the subject failed to mount the first female within $15 \mathrm{~min}$, this female was removed and replaced with a different sexually receptive female for the remainder of the test. The behaviors recorded for each subject were: (1) the number of mounts observed during the first $30 \mathrm{~min},(2)$ the latency to mount within the first $30 \mathrm{~min}$, (3) the number of intromissions in the first $30 \mathrm{~min}$, and (4) whether an ejaculation occurred.

The urine marking test was conducted 1 to 2 days after the second sexual behavior test. Males were individually placed on a piece of Whatman No. 2 filter paper, and a clean plastic cage, identical to the home cage, was inverted over each of them for $20 \mathrm{~min}$. After the filter papers dried, an observer counted the number of urine drops that had been deposited. The droplets were visualized by UV illumination (Desjardins et al., 1973).

Intermale aggression testing was conducted 3 days after the urine marking test. A single, 70-day-old, gonadally intact, group housed, socially subordinated (Scott, 1966), conspecific male was placed into the home cage of each subject for $10 \mathrm{~min}$. The behaviors recorded for each subject were: (1) the number of tail rattles, (2) the number of bites inflicted upon the intruding male, (3) the number of times the stimulus mouse was chased, and (4) the latencies of the first occurrences of each of the responses.

Histology and autopsy. After the completion of all behavioral testing, each VOX and SHAM animal was anesthetized with sodium pentobarbital and, $20 \mathrm{~min}$ later, was injected intraperitoneally with $30 \mu \mathrm{l}$ of an epinephrine solution $(1 \mathrm{mg} / \mathrm{ml}$ in saline) to facilitate the vomeronasal pumping mechanism which draws fluid into the VNO (Meredith and O'Connell, 1979; Macrides and Davis, 1983; Kream et al., 1981). The mice were placed on their backs and a $25 \%$ HRP solution $(7.5 \mathrm{mg}$ of $\mathrm{HRP}$ in $30 \mu \mathrm{l}$ of distilled water) was administered intranasally so that $15 \mu \mathrm{l}$ were passed into each external nare using the needle of a microliter syringe inserted 1 to $2 \mathrm{~mm}$ into the nostril. About $18 \mathrm{hr}$ later the animals were deeply anesthetized with sodium pentobarbital and perfused transcardially for 5 min with physiological saline, then for 30 min with a solution of $1.25 \%$ glutaraldehyde and $1 \%$ paraformaldehyde

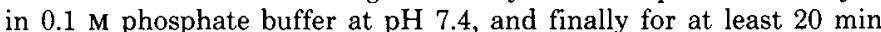
with a $10 \%$ sucrose $/ 0.1 \mathrm{M}$ phosphate buffer solution at $4^{\circ} \mathrm{C}, \mathrm{pH} 7.4$ (Mesulam, 1978; Rosene and Mesulam, 1978; Mesulam et al., 1980). Coronal, $40-\mu \mathrm{m}$-thick frozen sections were taken through the olfactory bulbs and every section containing the AOB was saved. Free-floating sections were reacted in a medium containing tetramethyl benzidine and $1 \% \mathrm{H}_{2} \mathrm{O}_{2}$ (Mesulam, 1978; Rosene and Mesulam, 1978; Mesulam et al., 1980). They were then mounted from water/gelatin onto plain microscope slides, air dried for about $24 \mathrm{hr}$, counterstained with neutral red, dehydrated in an ascending alcohol series, cleared with xylene, and coverslipped using DPX.

To assess the health and endocrine status of the mice, animals were 
weighed immediately before sacrifice. Both of the fixed testes were dissected from each subject and were cleaned and weighed. Fixed seminal vesicles were also dissected, cleaned, and weighed.

Statistical analysis. All statistical calculations involving the tabulated response latency measures were based on the scores of responding animals only. This was done to avoid assigning arbitrary latency scores to nonresponding mice. However, except where noted, the scores of all 20 animals were used in the statistical calculations involving measures of response frequency. Nonresponding mice were assigned the score of z.ero. The Mann-Whitney $U$ test or the Fisher exact probability test (Siegel, 1956) were used to compare the performances of the two groups. The binomial test (Siegel, 1956) was used to compare within-subject changes in the proportions of mating mice before and after surgery. In all cases, two-tailed probability values are reported. Corrections for tied observations were made in all calculations.

\section{Results}

Histological status. VNO lesions were verified by lavaging the nasal cavities of all animals with HRP. The HRP was actively incorporated and anterogradely transported within the peripheral main olfactory and vomeronasal afferents that were present in any given animal. The presence of HRP reaction product in the glomerular layers of either the MOB or $\mathrm{AOB}$ was taken as evidence that peripheral main olfactory or vomeronasal afferents, respectively, had been spared. Using this criterion, the peripheral extirpation of the VNO resulted in a specific and virtually complete bilateral peripheral deafferentation of the $A O B$ in all cases. No remaining vomeronasal nerve fragments could be visualized among animals in the VOX group. In contrast, HRP was bilaterally transported within the olfactory nerves of VOX mice, and all of these animals exhibited heavy bilateral anterograde HRP labeling within both the olfactory nerve and glomerular layers of the MOB. Figure $1 a$ depicts a typical MOB section from a VOX mouse at a level rostral to the AOB. Figure $1 b$ displays the AOB from a typical VOX mouse and demonstrates that peripheral VNO extirpation resulted in the elimination of the vomeronasal nerve, the absence of AOB anterograde HRP glomerular labeling, and a marked reduction of the AOB glomerular layer itself. The HRP distribution pattern among SHAM mice differed markedly from that among VOX animals in that all SHAM subjects demonstrated heavy, bilateral anterograde HRP glomerular labeling within both the $A O B$ and MOB. Figure $1 c$ depicts a typical MOB section from a SHAM mouse at a level rostral to the AOB. Figure $1 d$ displays an AOB section taken from a typical SHAM mouse.

Health and endocrine status. Body weights, seminal vesicle weights, and paired testes weights are presented in Table I. Body weights did not differ significantly between the two groups at the time of sacrifice. The paired testes weights of SHAM and VOX animals were not significantly different; neither were the seminal vesicle weights of the two groups found to differ significantly.

Sexual behavior. Table II depicts the sexual behavior of SHAM and VOX mice when tested with ovariectomized females. Most animals in both groups attempted to mount the ovariectomized, nonreceptive stimulus females, and in this respect the groups did not differ significantly. However, VOX mice were significantly slower to initiate mounting attempts than were SH $\Lambda \mathrm{M}$ mice $\left(U=11, n_{1}=7, n_{2}=8, p<0.05\right)$. Moreover, VOX mice tended to make fewer mounting attempts than did SHAM animals ( $U=25.5, n_{1}=10, n_{2}=10, p<0.06$ ).

When the animals were tested with sexually receptive stimulus females, a similar pattern of results emerged. Mice with lesions displayed less vigorous copulatory behavior than did sham-operated animals. These results are given in Table III. The VOX mice made significantly fewer mounts than did the SHAM animals ( $U=23.5, n_{1}=10, n_{2}=10, p<0.043$ ), although neither the proportion of males that mounted nor the mount latencies differed significantly between the two groups. Moreover, VOX mice made significantly fewer intromissions ( $U=$ 23.5, $n_{1}=10, n_{2}=10, p<0.029$ ) than did SHAM animals. The proportion of males within the two groups that intromitted and ejaculated did not differ significantly $(p=0.06)$, although the trend is in the expected direction ( 2 of 10 for the VOX group and 7 of 10 for the SHAM group). All mice ejaculated with females before surgery. After receiving sham operations, there was no significant reduction in the proportion of SHAM males that intromitted and ejaculated $(p>0.05)$. In contrast, a significant fraction of the VOX males that had intromitted and ejaculated prior to surgery failed to do so after surgery $(p<$ 0.008 ).

Urine marking. Urine marking rates did not differ significantly between experimental and control animals. All mice, regardless of experimental group, were observed to urine mark. 'The mean urine marking rate ( \pm SEM) of VOX males was 105 \pm 25 droplets. The urine marking rate of sham-operated animals was $98 \pm 16$ droplets.

Aggressive behavior. Table IV displays the intermale aggressive behavior of VOX and SHAM mice. All SHAM mice engaged in some form of aggressive behavior, be it either tail rattling, biting, or chasing. In contrast, only five VOX mice displayed any form of aggressive response. In this respect, VOX mice differed significantly from controls $(p<0.05)$. Similarly, as indicated in Table IV, a significantly smaller proportion of VOX than of SHAM mice displayed tail rattling $(p<0.05)$, biting $(p<0.02)$, or chasing $(p<0.02)$. In no case were stimulus males observed to initiate fighting, nor did they fight back if attacked. Two of the VOX males attempted to mount stimulus males late during the aggression tests. No VOX or SHAM males exhibited any fighting when stimulus females were presented during sexual behavior tests.

The behavior of the few VOX males that fought with stimulus males was, in general, indistinguishable from that expressed by SHAM mice. Thus, Table IV is constructed to emphasize the dichotomous nature of the VOX population. Specifically, mean response rates are expressed for each experimental population in two ways: first, as an average based upon the scores of only those mice that displayed specific responses, and second, as a group average based on 10 mice per group. When statistical calculations were based upon the scores of only those animals that responded, no significant group differences emerged. However, when statistical comparisons were based upon a population of 10 animals in each group, VOX males wère found to bite $\left(U=23, n_{1}=10, n_{2}=10, p<0.035\right)$ and chase $(U=22.5$, $\left.n_{1}=10, n_{2}=10, p<0.035\right)$ significantly less frequently than SHAM animals.

\section{Discussion}

Removal of the VNO produced a highly specific peripheral deafferentation of the $\mathrm{AOB}$ and resulted in marked reductions of social behaviors in male mice. As judged by the heavy, bilateral anterograde transport of intranasally applied HRP within the olfactory nerves to the glomerular layer of the MOB, animals in both the VOX and SHAM groups had functional main olfactory systems. Unlike the situation among VOX mice, in which the peripheral input to the $A O B$ was virtually eliminated, SHAM animals had funclional vomeronasal systems as judged by the heavy, bilateral anterograde transport of intranasally applied HRP within the vomeronasal nerves to the AOB glomerular layer. This pattern of group differences replicates previous observations that VNO afferents project to the AOB (Barber and Raisman, 1974). Peripheral deafferentation of the $\mathrm{AOB}$ resulted in significant reductions of copulatory behavior, a novel finding in male mice. In addition, the lesions significantly reduced the number of animals that displayed aggressive responses. Because urine marking patterns were not 

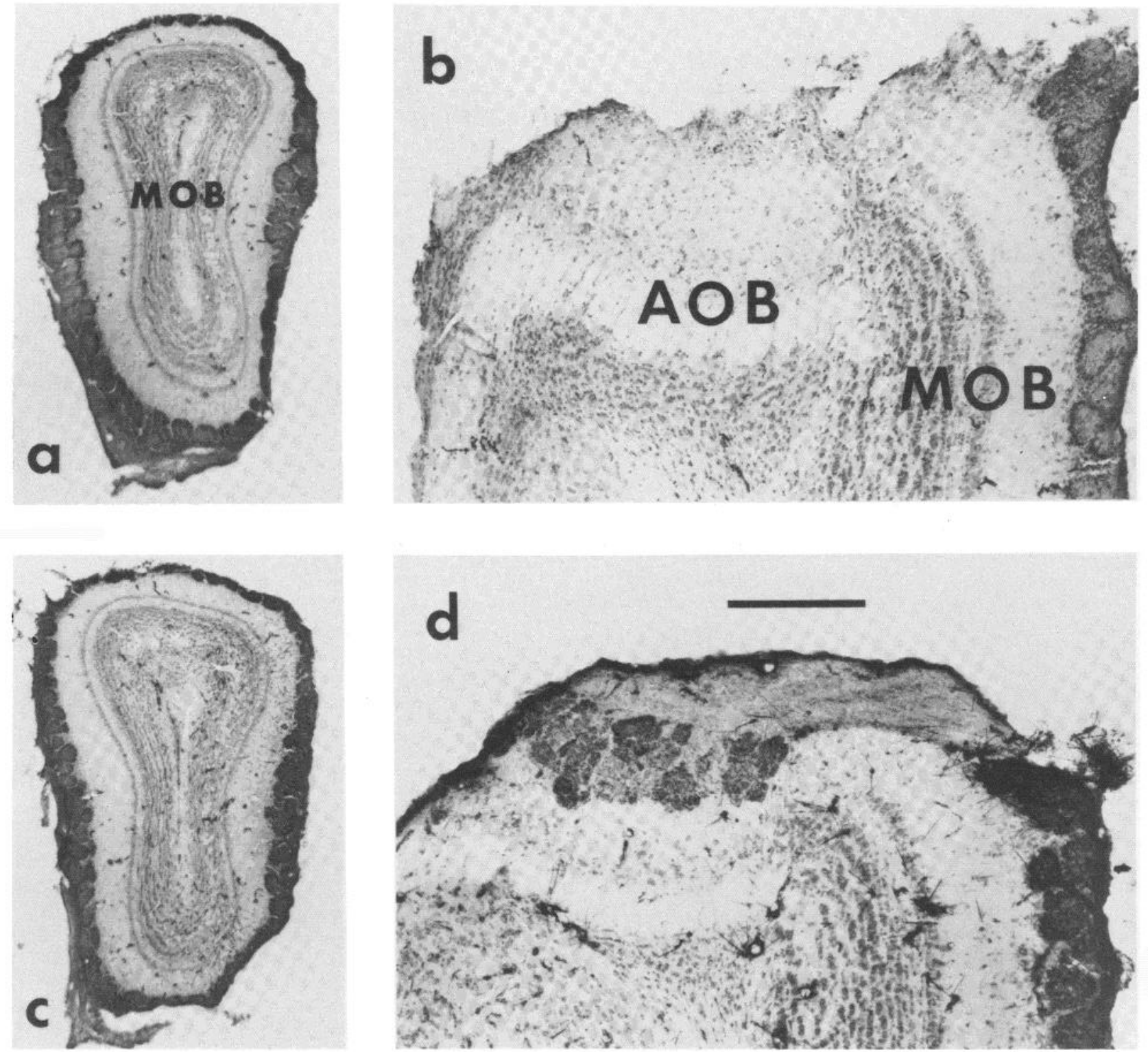

Figure 1. Selective peripheral deafferentation of the AOB. HRP was administered intranasally to male mice lacking their VNOs (Group VOX) and to sham-operated animals (Group SHAM) to visualize the peripheral vomeronasal and main olfactory afferents and their terminal fields within the AOB and MOB, respectively. Representative sections from a VOX animal are shown in $a$ and $b$ and sections from a SHAM animal are shown in $c$ and $d$. Heavy, bilateral, anterogradely transported HRP was present in the MOB after VNO removal $(a$ and $b)$, but no labeling occurred in the AOB $(b)$. In contrast, the peripheral afferents of both the MOB and AOB were heavily labeled after sham operations $(c$ and $d)$. Calibration bar: $650 \mu \mathrm{m}$ for $a$ and $c ; 200 \mu \mathrm{m}$ for $b$ and $d$.

TABLE I

Mean $\pm S E M$ body weights, paired testes weights, and seminal vesicle weights of male mice lacking their VNOs (Group VOX) and male mice that received sham operations (Group SHAM)

\begin{tabular}{lccc}
\hline Group $(n)^{a}$ & $\begin{array}{c}\text { Body Weight } \\
(\mathrm{gm})\end{array}$ & $\begin{array}{c}\text { Paired Testes } \\
\text { Weight } \\
(\mathrm{mg} / \mathrm{gm})\end{array}$ & $\begin{array}{c}\text { Seminal Vesicle } \\
\text { Weight } \\
(\mathrm{mg} / \mathrm{gm})\end{array}$ \\
\hline VOX $(10)$ & $36.33 \pm 1.33$ & $6.33 \pm 0.53$ & $6.95 \pm 0.50$ \\
SHAM $(10)$ & $37.13 \pm 0.62$ & $5.55 \pm 0.46$ & $6.50 \pm 0.46$ \\
\hline
\end{tabular}

${ }^{a}$ No statistically significant differences were detected between the animals of the two groups.

altered by the lesions, the reductions in sexual behavior and aggression cannot be attributed to a generalized behavioral impairment or performance decrement. The vomeronasal system may thus be implicated in the control of copulatory and aggressive behavior in mice.
TABLE II

The sexual behavior displayed by male mice lacking their VNOs (Group $V O X$ ) and animals that received sham operations (Group SHAM) when tested with ovariectomized, sexually unreceptive stimulus females

\begin{tabular}{lccc}
\hline Group ( $n$ ) & $\begin{array}{c}\text { No. of Mice } \\
\text { Attempting } \\
\text { Mount }\end{array}$ & $\begin{array}{c}\text { Attempted } \\
\text { Mount Latency } \\
\text { (Mean } \pm \text { SEM) }\end{array}$ & $\begin{array}{c}\text { Attempted } \\
\text { Mount Frequency } \\
\text { (Mean } \pm \text { SEM) }\end{array}$ \\
\hline & & $s e c$ & \\
VOX (10) & 7 & $560.4 \pm 74.0^{a}$ & $2.0 \pm 0.7$ \\
SHAM (10) & 8 & $341.0 \pm 51.2$ & $6.6 \pm 1.8$ \\
\hline
\end{tabular}

${ }^{a}$ Significantly different from SHAM values. Probability levels are given in the text.

There are several potential explanations for the behavioral effects of VNO excision. These various possibilities, which are not necessarily mutually exclusive, bear upon the role played by the vomeronasal system in the ultimate expression of sexual 
TABLE III

The sexual behavior displayed by male mice lacking their VNUs (Group VUX) and animals that received sham operations (Group SHAM) when tested with sexually receptive stimulus females

\begin{tabular}{lcccccc}
\hline Group ( $(n)$ & $\begin{array}{c}\text { No. of Mice } \\
\text { that Mounted }\end{array}$ & $\begin{array}{c}\text { No. of Mice } \\
\text { that Intromitted }\end{array}$ & $\begin{array}{c}\text { No. of Mice } \\
\text { that Ejaculated }\end{array}$ & $\begin{array}{c}\text { Mount Latency } \\
\text { (Mean } \pm \text { SEM) }\end{array}$ & $\begin{array}{c}\text { Mount Frequency } \\
\text { (Mean } \pm \text { SEM) }\end{array}$ & $\begin{array}{c}\text { Intromission Frequency } \\
\text { (Mean } \pm \text { SEM) }\end{array}$ \\
\hline & & & & sec & & \\
VOX (10) & 8 & $2^{a}$ & $2^{a}$ & $511.5 \pm 101.3$ & $4.8 \pm 1.3^{b}$ & $0.6 \pm 0.4^{b}$ \\
SHAM (10) & 10 & 7 & 7 & $351.7 \pm 52.4$ & $8.5 \pm 1.2$ & $3.5 \pm 1.2$ \\
\hline
\end{tabular}

${ }^{a}$ Significantly lower than presurgical level $(p<0.008)$.

${ }^{b}$ Significantly different from SHAM. Probability values are given in the text.

behavior and aggression in male mice. First, the reduced behavioral levels might have occurred because the lesions produced a chemosensory deficit that rendered VOX mice less able to detect conspecifics or to discriminate their gender. Second, in view of the close anatomical relationship between the vomeronasal system and amygdaloid and basal forebrain areas which have been implicated in the regulation of gonadal hormone secretion, peripheral $\mathrm{AOB}$ deafferentation might have produced chronic androgenic hormonal changes and a secondary alteration in the behavioral tendencies of the mice with lesions. Third, the vomeronasal system might contribute to behavioral arousal affecting the predisposition to engage in sexual or aggressive displays, perhaps by acutely modulating central neurochemical levels.

Several observations suggest that male mice lacking VNOs detected conspecifics and discriminated their gender. Most of the VOX mice attempted to mount receptive stimulus females and appeared to detect and approach them just as rapidly as the SHAM males. There was no significant difference in the mounting latencies of VOX and SHAM animals when tested with receptive females. Moreover, VOX mice appeared to discriminate between conspecific males and females since they rarely attempted to mount stimulus males and never fought with either receptive or unreceptive females. In a companion report (Coquelin et al., 1984) it is demonstrated that most VOX mice responded appropriately to conspecific ovariectomized females by exhibiting reflexive LH pulses. Nevertheless, unlike sham-operated male mice, animals lacking their VNOs failed to respond with reflexive hormonal surges when presented with urine obtained from conspecific females (Coquelin et al., 1984). This pattern of results emphasizes the role of the VNO in the reception of relatively specific chemosensory social cues but also suggests that other sensory systems contribute to the detection and social discrimination of conspecifics themselves.

Although male mouse sexual behavior (Champlin et al., 1963; McGill and Tucker, 1964; Edwards and Burge, 1971a, b) and aggression (Beeman, 1947; Edwards, 1969) are androgen dependent, chronic alterations in androgenic hormonal secretion cannot account for the impairments of VOX mice in their sexual and aggressive displays. No detectable differences in androgen-dependent organ weights were found between VOX and SHAM male mice in this study or in a recent study by Wysocki et al., (1982). Moreover, the failure of VNO extirpation to alter urine marking patterns, which is also an androgendependent behavior (Maruniak et al., 1977; Bronson, 1979), suggests that the changes in sexual and aggressive behavior were not due tu chronic alterations in androgenic secretion. Furthermore, neither resting plasma testosterone levels ( $\mathrm{Wy}$ socki et al., 1983) nor the normal pulsatile pattern of basal LH release (Coquelin et al., 1984) appear to be affected by VNO extirpation in male mice.

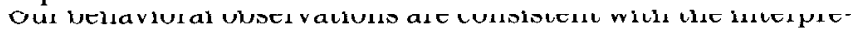
tation that male mice lacking VNOs recognized conspecifics but were less behaviorally aroused by them than were SHAM animals; i.e., the VOX mice less frequently fought with males or mounted, intromitted, and ejaculated with females, but rarely exhibited behaviors inappropriate to the gender of the stimulus animals. These behavioral results complement our finding that the female-elicited elevation of circulating $\mathrm{LH}$, although it occurred reliably in VOX mice, was modestly but significantly lower in its overall mean magnitude for the VOX animals as compared to the sham-operated mice (Coquelin et al., 1984). Although it is possible that group differences in acute hormonal responses to conspecifics contributed to the less robust social behavior of VOX males, it is more likely that such hormonal differences are secondary to neurochemical changes in VOX males and to reductions in their degree of behavioral arousal (cf. Macrides et al., 1977; Kream et al., 1984). For example, in comparison with other regions of the male mouse olfactory bulb, luteinizing hormone-releasing hormone (LHRH) is especially heavily concentrated within the posterior dorsal zone, the area occupied by the AOB (Dluzen and Ramirez, 1983). Moreover, $\mathrm{LHRH}$-immunoreactive fibers are widely distributed within the vomeronasal system (cf. Macrides and Davis, 1983). Within $15 \mathrm{~min}$ of being exposed to either conspecific stimulus males or females, significant elevations of LHRH occur in posterior dorsal but not anterior dorsal sectors of the male mouse olfactory bulb (Dluzen and Ramirez, 1983). Therefore, it is possible that the removal of the VNOs disturbs LHRH pathways or interferes with the acute regulation of $\mathrm{LHRH}$, a neuropeptide which has been implicated in the regulation of gonadotropin secretion and sexual behavior (Moss et al., 1975). The possible involvement of LHRH in the control of aggressive behavior has not yet been investigated. However, the current results, together with the recent finding that exposure to conspecific males elevates LHRH within the posterior dorsal male mouse olfactory bulb (Dluzen and Ramirez, 1983), raise the possibility that LHRH may also be involved in the regulation of intermale aggression.

Our behavioral results indicate that male mice detected, socially discriminated, and responded to conspecifics through the use of multiple sensory systems including the vomeronasal system. It is currently widely hypothesized that many social behaviors shown by rodents are dually mediated by neural systems associated with the AOB and MOB. For example, such dual mediation appears to be important in male hamster copulatory behavior, since mating was completely eliminated by dual peripheral olfactory system lesions which disturbed both the olfactory epithelium and the vomeronasal nerves but was partially spared when the lesions involved only one of these peripheral chemoreceptive systems (Powers and Winans, 1975; Winans and Powers, 1977). Neural systems associated with the $A O B$ and MOB might jointly participate in the mediation of male mouse copulatory behavior and aggression. At present, too few data relative to this hypothesis are available to make conclusive statements concerning male mouse sexual behavior (cf. Edwards et al., 1972; Rowe and Smith, 1972). However,

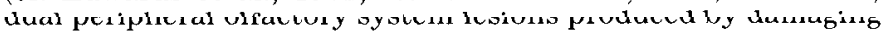
the olfactory epithelium with intranasally applied $\mathrm{ZnSO}_{4}$ and simultaneously transecting the vomeronasal nerves intracranially almost completely eliminated fighting shown by male mice (Bean, 1982a). Moreover, the dual lesions were more 


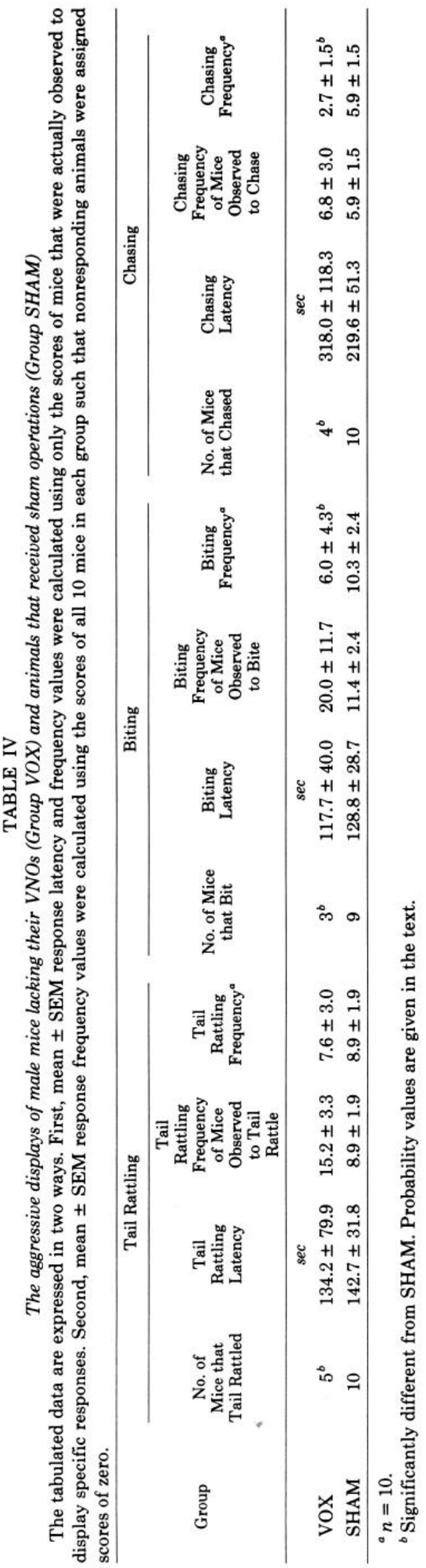

effective than single lesions directed to one peripheral chemoreceptive system only, even though vomeronasal nerve transection had a profound behavioral effect (Bean, 1982a).

Procedural differences between the current study and that of Bean (1982a) must be considered before it may be concluded that neural systems associated with the AOB and MOB jointly participate in the mediation of male mouse aggression. Bean (1982a) reported that all male mice with vomeronasal system damage showed a $50 \%$ to $100 \%$ reduction in their aggressive displays relative to their presurgical levels. In contrast, the mice in the current study were less uniformly impaired, in that half fought normally. In producing vomeronasal nerve damage, Bean (1982a) necessarily damaged the main olfactory bulbs, since an instrument was lowered into the main olfactory bulbs to transect the vomeronasal nerves. In contrast, because a peripheral surgical approach was employed in the current study, damage to the main olfactory system was prevented. Olfactory bulb damage has been shown to produce numerous neurochemical and degenerative alterations within the central nervous system, and thus, behavioral impairments associated with olfactory bulb damage cannot necessarily be attributed to sensory impairment, per se (Alberts, 1974; Cain, 1974; Hirsch, 1980; Hall and Macrides, 1983). Peripheral AOB differentiation accomplished by intracranial vomeronasal nerve transection may also be confounded by disruption of multiple neural and/or neurochemical systems due to direct bulb damage.

In conclusion, the vomeronasal system is importantly involved in the expression of sexual behavior and aggression in male mice. Peripheral extirpation of the VNOs in male mice produced a specific deafferentation of the AOB and significantly lowered copulatory and aggressive behaviors but did not interrupt the ability to discriminate the gender of conspecifics nor alter androgen-dependent organ weights. Thus, the behavioral changes produced by VNO ablation appear not to be due exclusively either to reduced chemosensory acuity or to indirect, androgen-mediated effects. Instead, our behavioral observations are consistent with the interpretation that male mice lacking VNOs were less behaviorally aroused than were shamoperated animals. Disturbances in LHRH pathways or with the acute regulation of $\mathrm{LHRH}$ might be partially responsible for these behavioral effects. Finally, neural pathways associated with the $\mathrm{AOB}$ and $\mathrm{MOB}$ might jointly mediate sexual and aggressive displays shown by male mice.

\section{References}

Alberts, J. R. (1974) Producing and interpreting olfactory deficits. Physiol. Behav. 12: 657-670.

Barber, P. C., and G. Raisman (1974) An autoradiographic investigation of the projection of the vomeronasal organ to the accessory olfactory bulb in the mouse. Brain Res. 81: 21-30.

Bean, N. J. (1982a) Modulation of agonistic behavior by the dual olfactory system in male mice. Physiol. Behav. 29: 433-437.

Bean, N. J. (1982b) Olfactory and vomeronasal mediation of ultrasonic vocalizations in male mice. Physiol. Behav. 28: 31-37.

Beeman, E. A. (1947) The effect of male hormone on aggressive behavior in mice. Physiol. Zool. 20: 373-405.

Bellringer, J. F., H. P. M. Pratt, and E. B. Keverne (1980) Involvement of the vomeronasal organ and prolactin in pheromonal induction of delayed implantation in mice. J. Reprod. Fertil. 59: 223-228.

Bermant, G., and L. Taylor (1969) Interactive effects of experience and olfactory bulb lesions in male rat copulation. Physiol Behav. 4: 1317.

Bronson, F. H. (1979) The reproductive ecology of the house mouse. Q. Rev. Biol. 54: 265-299.

Bronson, F. H., and C. Desjardins (1974) Circulating concentrations of FSH, LH, estradiol, and progesterone associated with acute, maleinduced puberty in female mice. Endocrinology $94: 1658-1668$.

Bronson, F. H., and H. E. Dezell (1968) Studies on the estrus-inducing (pheromonal) action of male deermouse urine. Gen. Comp. Endocrinol. 10: 339-343. 
Bronson, F. H., and B. E. Eleftheriou (1963) Infuence of strange males on implantation in the deermouse. Gen. Comp. Endocrinol. 3: 515518.

Bronson, F. H., and W. K. Whitten (1968) Oestrus-accelerating pheromone of mice: Assay, androgen-dependency and presence in bladder urine. J. Reprod. Fertil. 15: 131-134.

Bruce, H. M. (1959) An exteroceptive block to pregnancy in the mouse. Nature 184: 105 .

Bruce, H. M. (1965) Effect of castration on the reproductive pheromones of male mice. J. Reprod. Fertil. 10: 141143.

Cain, D. P. (1974) The role of the olfactory bulb in limbic mechanisms. Psychol. Bull. 81: 654-671.

Champlin, A. K., W. C. Blight, and T. E. McGill (1963) The effects of varying levels of testosterone on the sexual behavior of the male mouse. Anim. Behav. 11: 244-245.

Connor, J. (1972) Olfactory control of aggressive and sexual behavior in the mouse (Mus musculus L.). Psychon. Sci. 27: 1-3.

Coquelin, A., and F. H. Bronson (1980) Secretion of luteinizing hormone in male mice: Factors that influence release during sexual encounters. Endocrinology 106: 1224-1229.

Coquelin, A., A. N. Clancy, F. Macrides, E. P. Noble, and R. A. Gorski (1984) Pheromonally induced release of luteinizing hormone in male mice: Involvement of the vomeronasal system. J. Neurosci. $4: 2230$ 2236.

Denenberg, V. H., E. Gaulin-Kremer, R., Gandelman, and M. X. Zarrow (1973) The development of standard stimulus animals for mouse (Mus musculus) aggression testing by means of olfactory bulbectomy. Anim. Behav. 21: 590-598.

Desjardins, C., J. A. Maruniak, and F. H. Bronson (1973) Social rank in house mice: Differentiation revealed by ultraviolet visualization of urinary marking patterns. Science 182: 939-941.

Dluzen, D. E., and V. D. Ramirez (1983) Localized and discrete changes in neuropeptide (LHRH and TRH) and neurotransmitter (NE and DA) concentrations within the olfactory bulbs of male mice as a function of social interaction. Horm. Behav. 17: 139-145.

Edwards, D. A. (1969) Early androgen stimulation and aggressive behavior in male and female mice. Physiol. Behav. 4: 333-338.

Edwards, D. A. (1974) Non-sensory involvement of the olfactory bulbs in the mediation of social behaviors. Behav. Biol. 11: 287-302.

Edwards, D. A., and K. G. Burge (1971a) Early androgen treatment and male and female sexual behavior in mice. Horm. Behav. 2: 4958.

Edwards, D. A., and K. G. Burge (1971b) Estrogenic arousal of aggressive behavior and masculine sexual behavior in male and female mice. Horm. Behav. 2: 239-245.

Edwards, D. A. and K. G. Burge (1973) Olfactory control of the sexual behavior of male and female mice. Physiol. Behav. 11: 867-872.

Edwards, D. A., M. L. Thompson, and K. G. Burge (1972) Olfactory bulb removal vs. peripherally induced anosmia: Differential effects on aggressive behavior of male mice. Behav. Biol. 7: 823-888.

Edwards, R. G., E. D. Wilson, and R. E. Fowler (1963) Genetic and hormonal influences on ovulation and implantation in adult mice treated with gonadotropins. J. Endocrinol. 26: 389-399.

Gandelman, R., M. X. Zarrow, V. H. Denenberg, and M. Myers (1971) Olfactory bulb removal climinates maternal bchavior in the mouse. Science 171: 210-211.

Gandelman, R., M. X. Zarrow, and V. H. Denenberg (1972) Reproductive and maternal performance in the mouse following removal of the olfactory bulbs. J. Reprod. Fertil. 28: 453-456.

Hall, R. D., and F. Macrides (1983) Olfactory bulbectomy impairs the rat's radial-maze behavior. Physiol. Behav. 30: 797-803.

Haltmeyer, G. C., and K. B. Eik-Nes (1969) Plasma levels of testosterone in male rabbits following copulation. J. Reprod. Fertil. 19: 273277.

Heimer, L., and K. Larsson (1967) Mating behavior of male rats after olfactory bulb lesions. Physiol. Rehav. 2: 207-209.

Hirsch, J. D. (1980) The neurochemical sequelae of olfactory bulbectomy. Life Sci. 26: 1551-1559.

Johns, M. A., H. H. Feder, B. R. Komisaruk, and A. D. Mayer (1978) Urine-induced reflex ovulation in anovulatory rats may be a vomeronasal effect. Nature 272: $446-448$.

Kamel, F., and A. I. Frankel (1978) Hormone release during mating in the male rat: Time course, relation to sexual behavior, and interaction with handling procedures. Endocrinology 103: 2172-2179.

Kamel, F., E. J. Mock, W. W. Wright, and A. I. Frankel (1975)
Alteration in plasma concentrations of testosterone, $\mathrm{LH}$, and prolactin associated with mating in the rat. Horm. Behav. 6: 277-288.

Kamel, F., W. W. Wright, E. J. Mock, and A. I. Frankel (1977) The influence of mating and related stimuli on plasma levels of luteinizing hormones, follicle stimulating hormone, prolactin, and testosterone in male rats. Endocrinology 101: 421-429.

Kaneko, N., E. A. Debski, M. C. Wilson, and W. L. Whitten (1980) Puberty acceleration in mice. II. Evidence that the vomeronasal organ is a receptor for the primer pheromone in male mouse urine. Biol. Reprod. 22: 873878.

Katongole, C. B., F. Naftolin, and R. V. Short (1971) Relation between blood levels of luteinizing hormone and testosterone in bulls and the effects of sexual stimulation. J. Endocrinol. 50: 456-466.

Kennedy, J. M., and K. Brown (1970) Effects of male odor during infancy on the maturation, behavior, and reproduction of female mice. Dev. Psychobiol. 3: 179-189.

Kream, R. M., B. J. Davis, T. Kawano, F. L. Margolis, and F. Macrides (1984) Substance P and catecholaminergic expression in neurons of the hamster main olfactory bulb. J. Comp. Neurol. 222: 140-154.

Larsson, K. (1971) Impaired mating performances in male rats after anosmia induced peripherally or centrally. Brain Behav. Evol. 4: $463-471$.

Lehman, M. N., and S. S. Winans (1982) Vomeronasal and olfactory pathways to the amygdala controlling male hamster sexual behavior: Autoradiographic and behavioral analysis. Brain Res. 240: 27-41.

Lehman, M. N., S. S. Winans, and J. B. Powers (1980) Medial nucleus of the amygdala mediates chemosensory control of male hamster sexual behavior. Science 210: 557-560.

Leshner, A. I. (1978) An Introduction to Behavioral Endocrinology, Oxford University Press, New York.

Macrides, F., and B. J. Davis (1983) The olfactory bulb. In Chemical Neuroanatomy, P. C. Emson, ed., pp. 391-426, Raven Press, New York.

Macrides, F., A. Bartke, and S. Dalterio (1975) Strange females increase plasma testosterone levels in male mice. Science 189: 1104-1106.

Macrides, F., A. Bartke, F. Fernandes, and W. D'Angelo (1974) Effect of exposure to vaginal odor and receptive females on plasma testosterone in the male hamster. Neuroendocrinology 15: 355-364.

Macrides, F., A. Bartke, and B. Svare (1977) Interactions of olfactory stimuli and gonadal hormones in the regulation of rodent social behavior. In Olfaction and Taste VI, J. LeMagnen and P. MacLeod, eds., pp. 143-147, Information Retrieval Ltd., London.

Marques, D. M. (1979) Roles of the main olfactory and vomeronasal systems in the responses of the female hamster to young. Behav. Neural Biol. 26: 311-329.

Marsden, H. M., and F. H. Bronson (1964) Estrus synchrony in mice. Alteration by exposure to male urine. Science 144: 1469.

Maruniak, J. A., C. Desjardins, and F. H. Bronson (1977) Dominantsubordinate relationships in castrated male mice bearing testosterone implants. Am. J. Physiol. 233: E495-E499.

McGill, T. E., and G. R. Tucker (1964) Genotype and sex drive in intact and castrated male mice. Science 145: 514-515.

Meredith, M., and R. J. O'Connell (1979) Efferent control of stimulus access to the hamster vomeronasal organ. J. Physiol. (Lond.) 286: 301-316.

Meredith, M., D. M. Marques, R. J. O'Connell, and F. L. Stern (1980) Vomeronasal pump: Significance for male hamster sexual behavior. Science 207: 1224-1226.

Mesulam, M. M. (1978) Tetramethyl benzidine for horseradish peroxidase neurohistochemistry: A non-carcinogenic blue reaction-product with superior sensitivity for visualizing neural afferents and efferents. J. Histochem. Cytochem. 26: 106-117.

Mesulam, M. M., E. Hegarty, H. Barbas, K. A. Carson, E. C. Gower, A. G. Knapp, M. B. Moss, and E. J. Mufson (1980) Additional factors influencing sensitivity in the tetramethyl benzidine method for horseradish peroxidase neurohistochemistry. J. Histochem. Cytochem. 28: 1255-1259.

Moss, R. L. (1971) Modification of copulatory behavior in the female rat following olfactory bulb removal. J. Comp. Physiol. Psychol. 71: 374-382.

Moss, R. L., S. M. McCann, and C. A. Dudley (1975) Releasing hormones and sexual behavior. Prog. Brain Res. 42: 37-46.

Mugford, R. A., and N. W. Nowell (1970) Pheromones and their effect on aggression in mice. Nature 226: 967-968.

Murphy, M. R., and G. E. Schneider (1970) Olfactory bulb removal 
eliminates mating behavior in the male golden hamster. Science 167: 302-304.

Neckers, L. M., M. X. Zarrow, M. M. Myers, and V. H. Denenberg (1975) Influence of olfactory bulbectomy and the serotonergic system upon intermale aggression and maternal behavior in the mouse. Pharmacol. Biochem. Behav. 3: 545-550.

Powers, J. B., and S. S. Winans (1975) Vomeronasal organ: Critical role in mediating sexual behavior of the male hamster. Science 187: 961-963.

Purvis, K., and N. B. Ilaynes (1974) Short-term effects of copulation, human chorionic gonadotropin injection, and non-tactile association with a female on testosterone levels in the male rat. J. Endocrinol. 60: $429-439$.

Reynolds, J., and E. B. Keverne (1979) The accessory olfactory system and its role in the pheromonally mediated suppression of oestrus in grouped mice. J. Reprod. Fertil. 57: 31-35.

Ropartz, P. (1968) The relation between olfactory stimulation and aggressive behavior in mice. Anim. Behav. 16: 97-100.

Rosene, D. L., and M. M. Mesulam (1978) Fixation variables in horseradish peroxidase neurohistochemistry. I. The effects of fixation time and perfusion procedures upon enzyme activity. J. Histochem. Cytochem. 26: 28-39.

Rowe, F. A., and D. A. Edwards (1971) Olfactory bulb removal: Influence on the aggressive behaviors of male mice. Physiol. Behav. 7: 889-892.

Rowe, F. A., and D. A. Edwards (1972) Olfactory bulb removal: Influences on the mating behaviors of male mice. Physiol. Behav. 8: 3741.

Rowe, F. A., and W. E. Smith (1972) Effect of peripherally induced anosmia on mating behavior of male mice. Psychon. Sci. 27: 33-34.

Rowe, F. A., and W. E. Smith (1973) Simultaneous and successive olfactory bulb removal: Influences on the mating behavior of male mice. Physiol. Behav. 10: 443-449.

Saginor, M., and R. Horton (1968) Reflex release of gonadotropin and increased plasma testosterone concentration in male rabbits during copulation. Endocrinology 82: 627-630.

Scalia, F., and S. S. Winans (1975) The differential projections of the olfactory bulb and accessory olfactory bulb in mammals. J. Comp. Neurol. 161: 31-56.

Scott, J. P. (1966) Agonistic behavior of mice and rats: A review. Am.
Zool. 6: 683-701.

Siegel, S. (1956) Nonparametric Statistics, McGraw-Hill Book Co., New York.

Thompson, M. L., and D. A. Edwards (1972) Olfactory bulb ablation and hormonally induced mating in spayed female mice. Physiol. Behav. 8: 1141-1146.

Vandenbergh, J. G. (1967) Effects of the presence of a male on the sexual maturation of female mice. Endocrinology 81: 345-349.

Vandenbergh, J. G. (1969) Male odor accelerates female sexual maturation in mice. Endocrinology 84: 658-660.

Vandenbergh, J. G. (1973) Effects of central and peripheral anosmia on reproduction of female mice. Physiol. Behav. 10: 257-261.

Whitten, W. K. (1957) Effect of exteroceptive factors on the oestrus cycle of mice. Nature 180: 1436 .

Whitten, W. K., F. H. Bronson, and J. A. Greenstein (1968) Estrusinducing pheromone of male mice: Transport by movement of air. Science 161: 584-585.

Winans, S. S., and J. B. Powers (1974) Neonatal and two-stage olfactory bulbectomy effects on male hamster sexual behavior. Behav. Biol. 10: 461-471.

Winans, S. S., and J. B. Powers (1977) Olfactory and vomeronasal deafferentation of male hamsters: Histological and behavioral analysis. Brain Res. 126: 325-344.

Winans, S. S., and F. Scalia (1970) Amygdaloid nucleus: New afferent input from the vomeronasal organ. Science 170:330-332.

Wysocki, C. J. (1979) Neurobehavioral evidence for the involvement of the vomeronasal system in mammalian reproduction. Neurosci. Biobehav. Rev. 3: 301-341.

Wysocki, C. J., J. Nyby, G. Whitney, G. K. Beauchamp, and Y. Katz (1982) 'T'he vomeronasal organ: Primary role in mouse chemosensory gender recognition. Physiol. Behav. 29: 315-327.

Wysocki, C. J., Y. Katz, and R. Bernhard (1983) Male vomeronasal organ mediates female-induced testosterone surges in mice. Biol Reprod. 28: 917-922.

Zarrow, M. X., S. A. Estes, V. H. Denenberg, and J. H. Clark (1970) Pheromone facilitation and ovulation in the immature mouse. $\mathrm{J}$. Reprod. Fertil. 23: 357-360.

Zarrow, M. X., R. Gandelman, and V. H. Denenberg (1971) Lack of nest building and maternal behavior in the mouse following olfactory bulb removal. Horm. Behav. 2: 227-238. 